\title{
Sweet Wines Produced by an Innovative Winemaking Procedure: Colour, Active Odorants and Sensory Profile
}

\author{
M.J. Ruiz, L. Moyano, L. Zea* \\ Department of Agricultural Chemistry, University of Córdoba, Campus de Rabanales, Edificio Marie Curie, 14014 Córdoba, \\ Spain
}

Submitted for publication: October 2013

Accepted for publication: March 2014

Key words: Chamber-drying grapes, colour, aroma, oak chips, musts, sweet wines

\begin{abstract}
The colour, aroma-active compounds and sensory properties of sweet wines from Pedro Ximenez grapes produced by means of an innovative winemaking procedure, based on controlled chamber-drying of grapes, partial fermentation of the must (to $4 \%$ or $8 \%$ vol ethanol) and subsequent accelerated ageing by contact with oak chips, were studied. Fermentation made the musts less brown and more yellow, whereas ageing made them darker and increased their brown, reddish and yellowish hues. Overall, the musts fermented to $8 \%$ vol ethanol exhibited higher odour activity values (OAVs). In addition, the musts aged with oak chips were slightly different from those without chips. Expert tasters gave the highest scores to the musts fermented to $8 \%$ (v/v) ethanol with $2 \mathrm{~g} / \mathrm{L}$ of oak chips added. The winemaking process studied would allow the existing range of sweet wines from dried grapes to be expanded by using a fast, flexible, hygienic procedure.
\end{abstract}

\section{INTRODUCTION}

In recent years, Pedro Ximenez sweet wine has been under high demand from consumer and the volume produced is virtually sold out every season. The first and foremost step in the production process involves sun-drying the grapes, which face a high risk of deterioration from insect attacks, potential rain and nocturnal dew. In addition, these ambient conditions can favour the production of fungal toxins such as ochratoxin A (OTA), which have an adverse impact on the health and safety of Pedro Ximenez. Unquestionably, increased control over the conditions of grape drying result in better organoleptic and sanitary properties of the final musts. In this respect, Ruiz et al. (2010) have shown that chamber-drying grapes under controlled thermohygrometric conditions provides raisins of substantially improved quality. Chamber-drying for grapes is a fast and reliable method, independent of meteorological conditions.

The second important issue to consider is the high levels of sugars found in musts from dried grapes. High sugar content alters the metabolic activity of yeast and can delay, or even stop, alcoholic fermentation. Moreover, fermentation in sugar-rich media is known to lead to wines with high volatile acidity and sometimes with organoleptic faults, as outlined by García-Martínez et al. (2011). Using yeasts that are tolerant of high sugar and ethanol concentrations allows a rapid and reliable fermentation, reducing the risk of sluggish or stuck fermentation and microbial contamination. Logically, the selected yeast strain and the moment of when the fermentation is stopped can affect the wine quality in terms of composition and sensory profile. Furthermore, the OTA contents in wines can decrease during fermentation (Pérez-Serradilla \& Luque de Castro, 2008).

Another important consideration is the oxidative ageing in oak barrels. During this period of several years, wine acquires its characteristic bouquet as a result of significant changes due to different phenomena: esterification/ hydrolysis and redox reactions, spontaneous clarification, $\mathrm{CO}_{2}$ elimination, slow and continuous diffusion of oxygen through wood pores, and the extraction of tannins and aromatic substances from the wood to the wine (Camara et al., 2006). The different volatile compounds extracted from wood during this process (lactones, furanic compounds, vanillin derivatives, and phenol derivatives) have important sensory properties and contribute to the overall aroma of the wine.

However, ageing in oak casks takes a long time and is a very expensive process. A more economical alternative is the use of oak wood fragments. This practice first appeared in wines produced in emerging countries and later became authorised in the European Union (EU). Several studies have shown the technical possibilities of this practice (Guchu et al., 2006; Rodríguez-Bencomo et al., 2008). In addition, a recent study has shown that wines made with oak wood fragments are scarcely rejected by consumers (PérezMagariño et al., 2011). However, the sweetness, chromatic adjustment, aroma profile and complexity of the finally

*Corresponding author: qe1zecal@uco.es [Fax: +34957212146]

Acknowledgements: The authors are very grateful to Dr Carmen Millán, for her help in selecting and inoculating the yeast used. This work was funded by Spain's Ministry of Science and Technology 
wines depends of the ageing strategy. Therefore, different factors such as doses, size, form and toast level of fragments, ageing time and maceration conditions, must be studied to obtain wines with desirable sensory properties.

In this work, the colour, aroma profile and sensory properties of sweet wines from Pedro Ximenez grapes produced by an innovative winemaking procedure, based on chamber-drying of the grapes, partial fermentation of the must by osmo-ethanol-tolerant yeasts, and subsequent accelerated ageing by contact with oak chips, was studied. The results show that is possible to produce high-quality sweet wines from raisins by the fast, cheap and hygienic method proposed.

\section{MATERIALS AND METHODS}

\section{MUST SAMPLES}

Figure 1 depicts the experimental procedure described below. In this study, $200 \mathrm{~kg}$ of ripe Pedro Ximenez grapes were collected in the Montilla-Moriles region (southern Spain). Three batches of grapes of $25 \mathrm{~kg}$ each one were distributed uniformly $\left(14 \mathrm{~kg} / \mathrm{m}^{2}\right)$ in a single layer and dried in a chamber (Frisol Climatronic, Spain) at air temperatures of $40^{\circ} \mathrm{C}$ and humidity of $20 \%$. Samples were collected periodically and the sugar content of the grapes was measured by the Luff-Schoorl method (EEC, 1990). This method is based on the reduction of copper (II) ions in alkaline solution by the reducing sugars, followed by back titration of the remaining copper. The drying was concluded when the sugar concentration was around $450 \mathrm{~g} / \mathrm{L}$. The grapes were crushed and subsequently pressed in a vertical press similar to those used at the industrial level (EG-250 Sanahuja, Castellón, Spain). The highest pressure reached in each pressing cycle was 300 bars, and each grape batch was pressed in three cycles in a thermostatised chamber at $20^{\circ} \mathrm{C}$.

\section{Inoculation and fermentation}

A total of $21 \mathrm{~L}$ of must was supplied with $\mathrm{SO}_{2}$ at a concentration of $100 \mathrm{mg} / \mathrm{L}$, blended and distributed among seven $5000 \mathrm{~mL}$ Erlenmeyer flasks containing $3 \mathrm{~L}$ of must each. The samples were inoculated with a Saccharomyces cerevisiae strain X5 (CECT13015) previously isolated during spontaneous fermentation of musts from partially dried Pedro Ximenez grapes and chosen on the grounds of its tolerance to high sugar and ethanol concentrations in a previous experiment conducted at the Department of Microbiology of the University of Córdoba (García-Martínez et al., 2011). The starter cultures were prepared by growing each strain separately in YPD medium at $28^{\circ} \mathrm{C}$ for $2 \mathrm{~h}$, which was followed by centrifugation and washing with distilled water. Six flasks (two triplicates) were inoculated with $5 \mathrm{x}$ 106 cells $/ \mathrm{mL}$ and incubated at $25^{\circ} \mathrm{C}$, and the remaining $3 \mathrm{~L}$ of must was fortified to $18 \%(\mathrm{v} / \mathrm{v})$ ethanol and stored at $4^{\circ} \mathrm{C}$ in a cold chamber for use as the control.

The first three flasks were withdrawn from the chamber

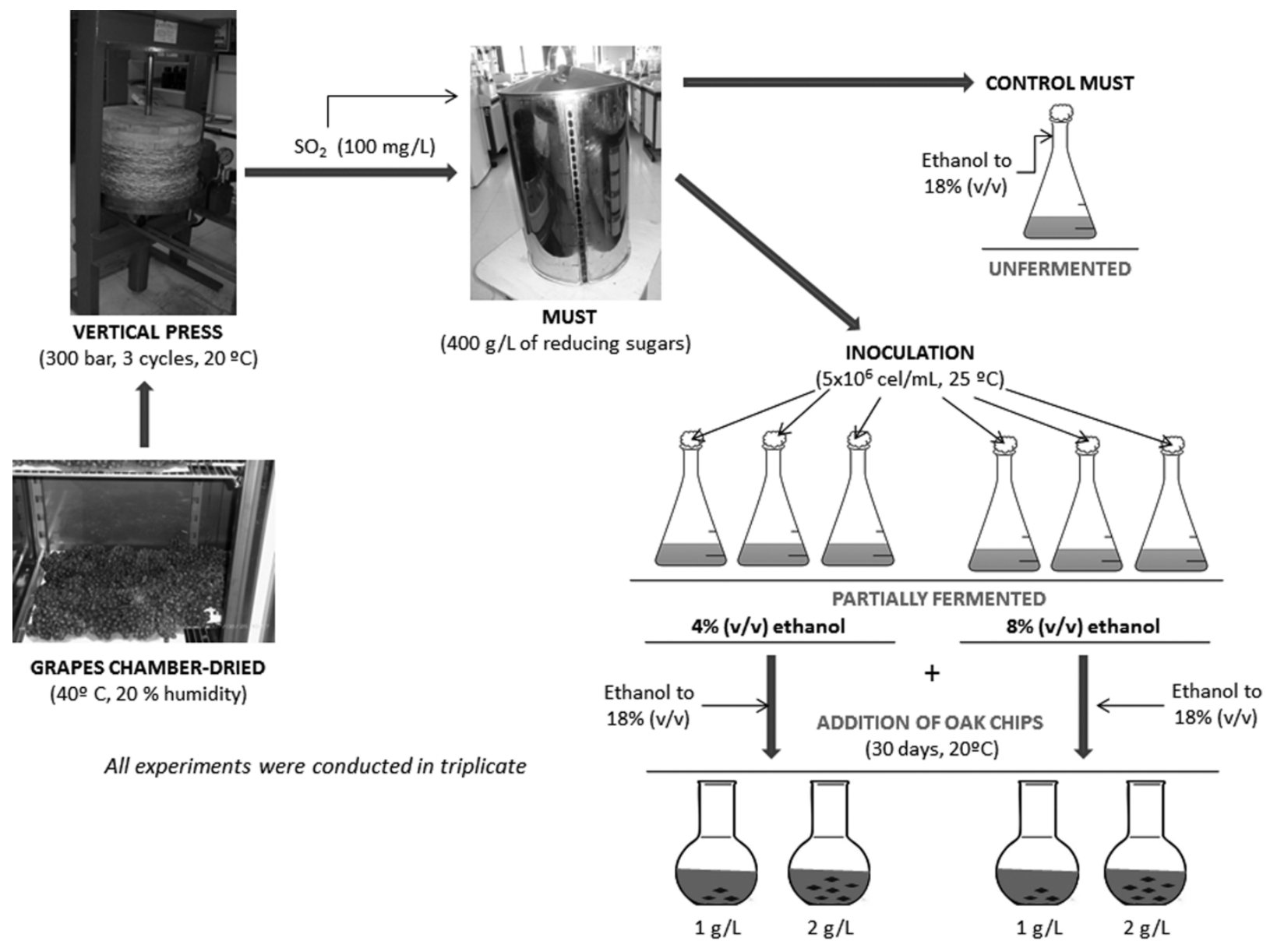

FIGURE 1

Experimental design followed in the study. 
when the ethanol content reached $4 \%(\mathrm{v} / \mathrm{v})$, which occurred after four days of incubation. The other three were withdrawn at an ethanol content of close to $8 \%(\mathrm{v} / \mathrm{v}), 14$ days after incubation. The fermentation process was monitored by the spectrophotometric method to measure ethanol (Crowell \& Ough, 1979). Both batches were immediately fortified to $18 \%$ vol with wine alcohol (Alcoholes del Sur, Córdoba, Spain; CE 200-578-6), centrifuged at $3000 \mathrm{rpm}$ at $4^{\circ} \mathrm{C}$ for $10 \mathrm{~min}$ and stored in a cold chamber at $4^{\circ} \mathrm{C}$ until analysis.

\section{Accelerated ageing}

The accelerated ageing experiment was conducted on 3000 $\mathrm{mL}$ of each fermented must, which was distributed among six $1000 \mathrm{~mL}$ flasks to obtain two batches consisting of six $500 \mathrm{~mL}$ samples each. Three flasks in each batch were supplied with American oak in the form of medium-toasted chips (Anatride Ibérica SL, Zaragoza, Spain) at a concentration of $1 \mathrm{~g} / \mathrm{L}$, and the other three with a $2 \mathrm{~g} / \mathrm{L}$ concentration of identical chips. The flasks were then stoppered with hydrophobic cotton and allowed to stand in a thermostated room at $20^{\circ} \mathrm{C}$ for 30 days, with shaking by hand on a daily basis. After the experiment was finished, the wood chips were removed and the samples were stored in a cold chamber at $4{ }^{\circ} \mathrm{C}$ until analysis.

\section{Conventional analyses}

The $\mathrm{pH}$, total and volatile acidities and reducing sugars were determined according to EEC (1990) methods. Glycerine was quantified by direct injection of samples in a gas chromatograph HP 6890 GC System (Agilent Technologies, CA, USA) equipped with a capillary column with molten silica CP-WAX 57 CB (50 m x $0.25 \mathrm{~mm}$ x $0.4 \mu \mathrm{m}$ thickness), and a FID was used as the detector according to Peinado et al. (2004).

\section{Browning and colour evaluation}

Browning of the samples was measured as absorbance at $420 \mathrm{~nm}$. Colour was determined according to the recommendations of the International Commission on Illumination (CIE, 2004) with the illuminant D65 (daylight source) and $10^{\circ}$ standard observer (perception of a human observer). The parameters calculated were $\mathrm{a}^{*}$ (red/green values), $b^{*}$ (yellow/blue values), and $\mathrm{L}^{*}$ (lightness). From the CIELab space, other psychophysical parameters were calculated, such as $\mathrm{C}^{*}$ (chroma or saturation) and h (hue angle). All the respective measurements were carried out in triplicate in a Perkin-Elmer Lambda 25 model spectrophotometer (USA) using $10 \mathrm{~mm}$ quartz tray after filtering the samples through a HA- $0.45 \mu \mathrm{m}$ paper(Millipore).

\section{Identification and quantification of aroma compounds}

Each aroma compound was identified by means of its retention time, co-eluted with a standard solution of commercial product (Sigma Aldrich, Munich, Germany), and confirmed by mass spectrometry (Hewlett-Packard 5972 MSD, Agilent Technologies, CA, USA). Positive ion electron impact mass spectra were acquired in scan mode, with a range of $\mathrm{m} / \mathrm{z} 39$ to 300 , and a scan rate of $1.6 \mathrm{scans} / \mathrm{sec}$. For each compound the mass spectra were confirmed by comparison with the Wiley mass spectral library. The chromatographic column, injector and oven temperatures, carrier gas and its flow were the same as those used for the quantification, as described below.

For the quantification of the aroma compounds, samples of $100 \mathrm{~mL}$ were adjusted to $\mathrm{pH} 3.5,150 \mathrm{mg}$ of 2-octanol was added as an internal standard and then extracted with $100 \mathrm{~mL}$ of freon-11 (Sigma-Aldrich Química S.A., Madrid, Spain) in a continuous extractor for 24 hours. After concentration of the freon extracts to $0.2 \mathrm{~mL}$ in a Kuderna-Danish microconcentrator, $3 \mu \mathrm{L}$ were injected into the Hewlett-Packard 5890 series II chromatograph with an HP-INNOWax column of $60 \mathrm{~m} \times 0.32 \mathrm{~mm} \times 0.25 \mu \mathrm{m}$ thickness (Agilent Technologies, CA, USA), equipped with a split/splitless injector and an FID detector. The oven temperature programme was as follows: $5 \mathrm{~min}$ at $45^{\circ} \mathrm{C}, 1^{\circ} \mathrm{C} / \mathrm{min}$ up to $185^{\circ} \mathrm{C}$ and $30 \mathrm{~min}$ at $185^{\circ} \mathrm{C}$. Injector and detector temperatures were $275^{\circ} \mathrm{C}$ and $300^{\circ} \mathrm{C}$ respectively. The carrier gas was helium at $70 \mathrm{kPa}$ and was split 1:30. The quantification was made by using chromatographic response factors, calculated for each compound in relation to the internal standard, in standard solutions of commercial products (purity $>95 \%$ ) supplied by Sigma Aldrich (Munich, Germany). The quantification was done in triplicate.

\section{Odour descriptors of aroma compounds}

For the determination of odour descriptors, a direct olfaction of the pure reference standards (Sigma Aldrich, Munich, Germany) was conducted on water solutions of each compound with a concentration slightly higher than its perception threshold (10\%). The taste panel consisted of 20 trained judges of both sexes ( 12 female and 8 male) between the ages of 20 and 55 years (ISO 5496:1992) from the University of Cordoba. All judges were trained in preliminary sessions using reference standards taken from Sigma-Aldrich (Munich, Germany) and from "Le nez du vin" (Jean Lenoir, Provence, France) according to ISO 5496:1992. Thirteen judges of the above-mentioned panel had previous experience in the sensory evaluation of sherry wine. During the training, five standards were tasted per session and were discussed by the judges in terms of odour descriptors, and consensus on the terms was reached by eliminating those that were considered irrelevant or redundant. Later, five different odour samples were served at each session and there were 13 evaluation sessions. Samples were prepared $30 \mathrm{~min}$ before the test to allow time for the vapour pressure to reach equilibrium at ambient temperature. The odour substances $(1 \mathrm{~mL})$ were poured directly into the glass flasks containing a piece of cotton and were closed immediately. Evaluation was conducted in our laboratory in individual booths at room temperature $\left(25^{\circ} \mathrm{C}\right)$. The responses of the judges were compiled for all aroma compounds, and those odour descriptors cited by less than $15 \%$ of the panel were eliminated. The odour descriptors are listed in Table 1.

\section{Sensory analysis of wines}

The partially fermented musts treated with oak wood chips were subjected to a quantitative descriptive analysis (QDA) to establish their sensory profile (Stone et al., 2012). The tasting panel was composed of five experts (three men and two women, 40 to 50 years old), selected by the Quality Regulation Board of the Montilla-Moriles designation 
TABLE 1

Odour descriptors, odorant terms (Wine Aroma Wheel) and perception thresholds $(\mu \mathrm{g} / \mathrm{L})$ of the aroma compounds determined in the sweet wines.

\begin{tabular}{|c|c|c|c|}
\hline Compound & Odour descriptor & Odorant terms & Threshold \\
\hline Ethyl acetate & Pineapple, varnish, anise & Tropical fruit, pungent, spicy & $7500^{\mathrm{a}}$ \\
\hline 1,1-Diethoxyethane & Green fruit, liquorice & Tree fruit, spicy & $1000^{\mathrm{a}}$ \\
\hline Propyl acetate & Glue, Christmas sweet & Chemical, caramelised & $65000^{\mathrm{a}}$ \\
\hline 2,3-Butanedione & Buttery & Caramelised & $100^{\mathrm{a}}$ \\
\hline Ethyl propanoate & Apple & Tree fruit & $5000^{\mathrm{a}}$ \\
\hline Isobutyl acetate & Sweet, apple, banana & Caramelised, tree fruit, tropical fruit & $6140^{a}$ \\
\hline 2-Butanol & Vinous & Chemical & $1000000^{\mathrm{a}}$ \\
\hline 2,3-Pentanedione & Buttery & Caramelised & $1000^{\mathrm{b}}$ \\
\hline Butyl acetate & Ripe pear, glue & Tree fruit, chemical & $4600^{a}$ \\
\hline Hexanal & Green & Fresh & $350^{\mathrm{c}}$ \\
\hline Isobutanol & Alcohol, nail polish & Chemical, pungent & $40000^{\mathrm{a}}$ \\
\hline Isoamyl acetate & Banana & Tropical fruit & $30^{\mathrm{a}}$ \\
\hline 1-Butanol & Medicinal & Phenolic & $820000^{\mathrm{a}}$ \\
\hline Isoamyl alcohols & Alcohol, nail polish & Chemical, pungent & $65000^{\mathrm{a}}$ \\
\hline Ethyl hexanoate & Banana, green apple & Tropical fruit, tree fruit & $5^{\mathrm{a}}$ \\
\hline Isoamyl butanoate & Banana & Tropical fruit & $1000^{\mathrm{c}}$ \\
\hline Hexyl acetate & Apple, banana & Tree fruit, tropical fruit & $1000^{\mathrm{b}}$ \\
\hline Octanal & Soapy, fatty, honey, grass & Chemical, oily, caramelised, fresh & $640^{a}$ \\
\hline Acetoin & Buttery, cream & Caramelised & $30000^{\mathrm{a}}$ \\
\hline Ethyl heptanoate & Sweet, strawberry, banana & Caramelised, berry, tropical fruit & $10000^{\mathrm{d}}$ \\
\hline 3-Methylpentanol & Pungent, vinous, cacao, herbaceous & Pungent, chemical, caramelised, fresh & $50000^{\mathrm{a}}$ \\
\hline Ethyl lactate & Strawberry, raspberry, buttery & Berry, caramelised & $100000^{\mathrm{a}}$ \\
\hline 1-Hexanol & Green, grass & Fresh & $8000^{\mathrm{a}}$ \\
\hline E-3-hexenol & Grass, resinous, cream & Fresh, resinous, caramelised & $1000^{\mathrm{c}}$ \\
\hline 3-Etoxypropanol & Overripe pear & Tree fruit & $50000^{\mathrm{a}}$ \\
\hline E-2-hexenol & Green & Fresh & $15000^{c}$ \\
\hline Furfural & Burned almond, floral & Burned, floral, marshmallow & $15000^{\mathrm{a}}$ \\
\hline Ethyl 3-hidroxybutanoate & Fresh, grape & Fresh, berry, floral & $67000^{\mathrm{a}}$ \\
\hline Benzaldehyde & Bitter almond, nutty, smoky & Nutty, burned & $5000^{\mathrm{a}}$ \\
\hline Isobutanoic acid & Rancid butter & Lactic & $20000^{\mathrm{a}}$ \\
\hline 5-Methylfurfural & Bitter almond, spicy & Nutty, spicy & $16000^{\mathrm{a}}$ \\
\hline$\gamma$-Butyrolactone & Coconut, caramel & Tropical fruit, caramelized & $100000^{\mathrm{a}}$ \\
\hline Butanoic acid & Rancid, cheese & Lactic & $10000^{\mathrm{a}}$ \\
\hline Furfuryl alcohol & Medicinal & Phenolic & $15000^{\mathrm{a}}$ \\
\hline Diethyl succinate & Lavender, overripe melon & Caramelized, floral, tropical fruit & $100000^{\mathrm{a}}$ \\
\hline 3-Methylbutanoic acid & Parmesan cheese, rancid & Lactic & $3000^{\mathrm{a}}$ \\
\hline$\alpha$-Terpineol & Lilac & Floral & $38000^{\mathrm{a}}$ \\
\hline$\gamma$-Hexalactone & Coconut, almond liqueur, sweet & Tropical fruit, nutty, caramelised & $359000^{d}$ \\
\hline Methionol & Cut hay, cooked potato & Fresh & $500^{\mathrm{a}}$ \\
\hline Geranial & Citrus, sweet & Citrus, caramelised & $1000^{\mathrm{c}}$ \\
\hline Nerol & Herbaceous, lemon balm & Fresh, floral & $10000^{\mathrm{c}}$ \\
\hline$\gamma$-Heptalactone & Coconut, herbaceous, caramel & Tropical fruit, fresh, caramelised & $1000^{\mathrm{c}}$ \\
\hline 2-Phenylethanol acetate & Rose, honey & Floral, caramelised & $250^{\mathrm{a}}$ \\
\hline Hexanoic acid & Cheese & Lactic & $3000^{\mathrm{a}}$ \\
\hline Guaiacol & Smoky & Burned & $20^{\mathrm{e}}$ \\
\hline Benzyl alcohol & Fruity, walnut & Tree fruit, nutty & $900000^{\mathrm{a}}$ \\
\hline E-oak lactone & Coconut, burned wood, vanilla & Tropical fruit, burned, spicy & $122^{\mathrm{a}}$ \\
\hline
\end{tabular}


TABLE 1 (CONTINUED)

\begin{tabular}{|c|c|c|c|}
\hline Compound & Odour descriptor & Odorant terms & Threshold \\
\hline 2-Phenylethanol & Rose, honey & Floral, caramelised & $10000^{a}$ \\
\hline Z-oak lactone & Coconut, burned wood, vanilla & Tropical fruit, burned, spicy & $35^{\mathrm{a}}$ \\
\hline Methyleugenol & Clove & Spicy & $10000^{\mathrm{d}}$ \\
\hline 4-Ethylguaiacol & Smoky, clove & Burned, spicy & $46^{\mathrm{a}}$ \\
\hline Diethyl malate & Peach, prune & Tree fruit & $760000^{\mathrm{a}}$ \\
\hline Pantolactone & Liquorice, smoky & Spicy, burned & $500000^{\mathrm{a}}$ \\
\hline Octanoic acid & Oily, rancid & Oily, lactic & $8800^{\mathrm{a}}$ \\
\hline 2-Phenylethanol hexanoate & Overripe banana, sweet & Tropical fruit, caramelised & $50000^{c}$ \\
\hline Eugenol & Clove & Spicy & $5^{\mathrm{a}}$ \\
\hline$\gamma$-Decalactone & Peach & Tree fruit & $1000^{\mathrm{a}}$ \\
\hline 4-Ethylphenol & Spicy & Spicy & $140000^{\mathrm{a}}$ \\
\hline Syringol & Smoky & Burned & $1700^{\mathrm{e}}$ \\
\hline Decanoic acid & Rancid, waxy & Lactic, oily & $15000^{\mathrm{a}}$ \\
\hline Farnesol & Fruity, balsamic, floral, clove & Tree fruit, fresh, floral, spicy & $72000^{\mathrm{c}}$ \\
\hline Isoeugenol & Clove, burned wood, sweet & Spicy, burned, caramelised & $6^{\mathrm{c}}$ \\
\hline Monoethyl succinate & Burned caramel, coffee & Burned & $1000000^{\mathrm{c}}$ \\
\hline Vanillin & Vanilla & Spicy & $65^{\mathrm{e}}$ \\
\hline 2,3-Butanediol & Sweet, creamy, butter & Caramelised & $668000^{\mathrm{a}}$ \\
\hline
\end{tabular}

$\mathrm{a}=$ from Zea et al. (2007)

$\mathrm{b}=$ from Chaves et al. $(2007)$

$\mathrm{c}=$ determined by the author in alcoholic solution; data not published. Five solutions of ascending concentration of these compounds were used. Starting from the lowest concentration solution, the judges indicated odorant sensations different to that perceived in the control (distilled water), according to the ISO 5495:1983.

$\mathrm{d}=$ from Moreno (2005)

$\mathrm{e}=$ from Moyano et al. (2012)

of origin (southern Spain). These judges are professional oenologists who know the characteristics of typical wines produced in the region very well, and therefore are sensitive to even small differences.

The tasting session was preceded by another one to reach consensus on the sensory attributes used in the sensory analysis of the sweet musts studied (fermentative aroma, woody, astringency, sweetness, acidity and colour). The performance of the expert tasters was accepted as highly reliable and consistent according to the abovementioned Quality Regulation Board. In three consecutive sessions, the tasters examined the seven samples of wine three times, with the ones being presented in random order each time. Their sensory attributes, sensory balance and global impression were scored using the scale method in accordance with ISO 4121:1987. The scale direction goes from left to right with increasing intensities: 1 (imperceptible), 2 (weak), 3 (moderate), 4 (strong) and 5 (excessive) (Stone et al., 2012). Balance and global impression were measured on a five-point hedonic scale, from 1 (unacceptable) to 5 (highly acceptable), with three intermediate points. The results were given as mean \pm standard deviation. The means of the sample scores were shown in a "spider web" graph.

Samples were stored in a refrigerator and withdrawn one hour before the sensory test in order to facilitate the adjustment in temperature to that of the tasting room. Evaluation was carried out in a thermostated room with individual booths at $20^{\circ} \mathrm{C}$. Twenty millilitres of sample were used in standardised wine glasses (ISO 3591:1992). These were marked with a code and covered to avoid any loss of organoleptic properties. The sequence of sample presentation went from wines with $4 \%(\mathrm{v} / \mathrm{v})$ to those with $8 \%(\mathrm{v} / \mathrm{v})$ alcohol content. All the samples were evaluated in a single session, one at a time, with a wait of 3 min between samples.

\section{Statistical treatments}

ANOVA (LSD 95\% level) was performed on the triplicates of winemaking variables studied. The OAVs for odorant term and the results of the sensory analysis of the wines were calculated as mean \pm standard deviation of three samples for each wine type. To find which variables contributed most to the difference in the aroma profiles of the wines, a PCA was performed on the triplicates of OAVs of odorant terms. The values of the variables were standardised by subtracting their means and dividing by their standard deviations. Results were validated by full internal cross-validation.

\section{Software}

Statgraphics $^{\mathrm{TM}}$ (Version 5.0). STSC Inc, Rockville, MD, USA.

\section{RESULTS AND DISCUSSION \\ Winemaking variables}

Table 2 shows the conventional oenological and colour parameters of the musts. The ANOVA shows that wines with different alcohol levels obtained by fermentation also 


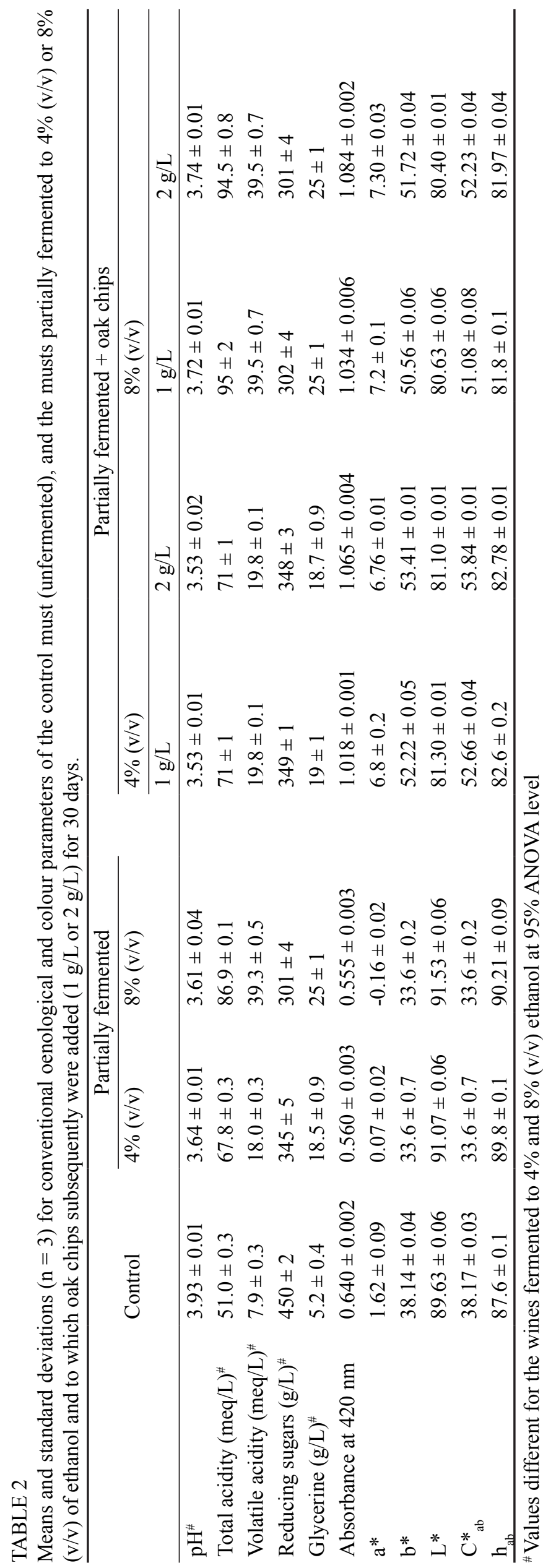

presented values of $\mathrm{pH}$, total and volatile acidity, reducing sugar and glycerine that were different in each case at the LSD 95\% level. This shows that the fermentations progressed successfully. As can be seen in Table 2, alcoholic fermentation lowered the $\mathrm{pH}$, and increased the total and volatile acidity markedly. This suggests that, as previously found by other authors (Pigeau et al., 2002; Erasmus et al., 2004; Malacrino et al., 2005), the yeasts produced increased amounts of acetic acid in response to the osmotic stress caused by high sugar levels. In general, high levels of volatile acidity are not considered positive for quality of wine. However, for the sweet wines, the increased production of acetic acid countered the overall sweetness in the end-product through its contribution to total acidity (Pigeau et al., 2007).

Obviously, the levels of reducing sugars decreased as a result of fermentation, especially in the musts fermented to $8 \%(\mathrm{v} / \mathrm{v})$ ethanol (about $300 \mathrm{~g} / \mathrm{L}$ ) and irrespective of the ageing procedure. Also, glycerine increased markedly, with average concentrations close to 18 and $25 \mathrm{~g} / \mathrm{L}$ in the musts fermented to 4 and $8 \%$ respectively, even after ageing. These high glycerine levels are the result of the osmotic stress of the yeasts. Glycerine has been proposed by several authors to be one of the most compatible metabolites to equilibrate the osmotic pressure in the cell with the use of glycerine-3phosphate dehydrogenase.

Fermentation decreased the colour-related parameters, $\mathrm{A}_{420}, \mathrm{a}^{*}, \mathrm{~b}^{*}$ and $\mathrm{C}_{\mathrm{ab}}{ }^{*}$, and increased $\mathrm{L}^{*}$ and $\mathrm{h}_{\mathrm{ab}}$; the resulting sweet wines were thus less brown and more pale. This may have been the result of yeasts adsorbing some coloured compounds during fermentation (Mérida et al., 2005) and/or of low $\beta$-glucosidase activity in the yeasts. On the other hand, accelerated ageing increased $\mathrm{A}_{420}, \mathrm{a}^{*}, \mathrm{~b}^{*}$ and $\mathrm{C}_{\mathrm{ab}}{ }^{*}$, and decreased $\mathrm{L}^{*}$ and $\mathrm{h}_{\mathrm{ab}}$, with the resulting wines exhibiting increased brown, dark, reddish and yellowish hues, especially at the higher wood chip concentration. This dissimilar behaviour may have been the result of oxidation, condensation and/or polymerisation reactions, and also of the extraction of mainly phenolic compounds from the chips.

\section{Aroma compounds}

Table 3 lists the contents of the compounds studied in the sweet wines. The odour activity value (OAV) for each compound was calculated by dividing its concentration in the samples by the concentration corresponding to its odour threshold (Table 1). Over the past few years, numerous authors have proposed an approximation of the importance of a flavour compound in the wine based on the OAV. However, quantifying the perceived intensity of odorants and their contribution to the overall aroma is more complex.

Based on the perception thresholds shown in Table 1 , there were only 12 active odorants $(\mathrm{OAV}>1)$ in at least one sample. 2,3-Butanedione (diacetyl) is one of the typical odorants in musts from dried Pedro Ximenez grapes (Ruiz et al., 2010), which it endows with buttery notes. The musts fermented to $4 \%(\mathrm{v} / \mathrm{v})$ ethanol exhibited higher OAVs (approximately 29.5), which suggests that the point at which the fermentation process is stopped influences the final concentrations of this compound. It is most likely that the reductive conditions prevailing at the end of alcoholic fermentation facilitate the reduction of 2,3-butanedione to 2,3-butane- 


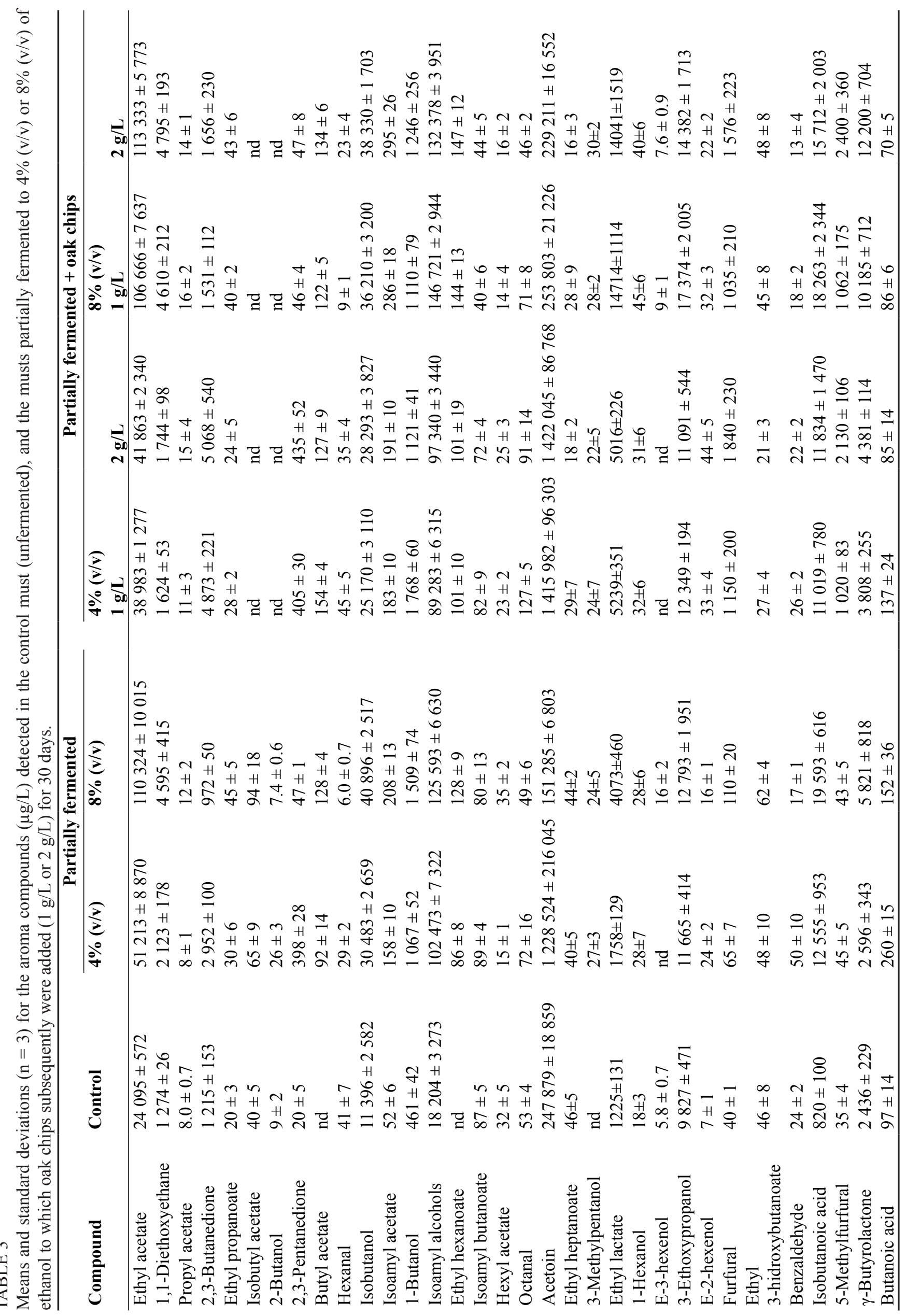




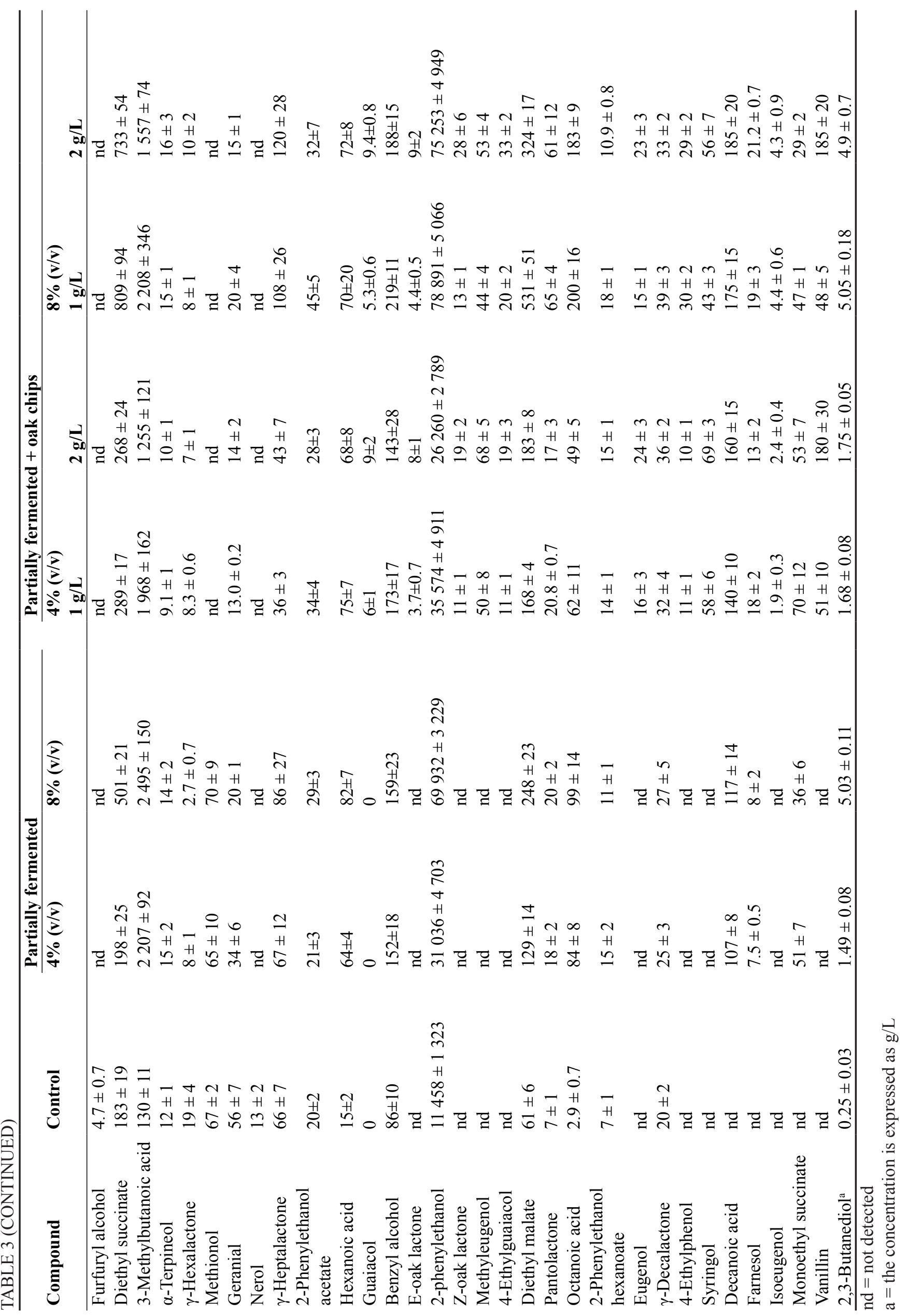


diol, thereby diminishing its impact on the aroma (Martineau et al., 1995). The odorant activity of 2,3-butanediol increased markedly during fermentation and the compound reached its highest OAVs $(\approx 7.5)$ in the must fermented to $8 \%(\mathrm{v} / \mathrm{v})$ ethanol. This compound is associated with sweet, creamy, buttery notes.

The higher alcohols isobutanol, isoamyl and 2-phenylethanol only reached their perception thresholds at the end of fermentation; however, they exhibited near-unity OAVs, so it is reasonable to assume that they can hardly have contributed to the overall aroma of the sweet wines studied.

Ethyl hexanoate and isoamyl and ethyl acetates exhibited the highest odorant activity in the partially fermented musts and thus were major contributors to their aroma profile, which they enriched with fruity, anise and varnish notes. Ruiz et al. (2010) previously found ethyl acetate to increase during the drying of Pedro Ximenez grapes, both in the sun and in chambers, through the effect of its involvement in anaerobic metabolism in the grape berries during drying. Also, this compound has been deemed a useful marker for metabolism in drying grape berries (Chkaiban et al., 2007).

1,1-Diethoxyethane (diacetal) slightly surpassed its perception threshold in the unfermented must, and its concentration increased, also slightly, from the effect of fermentation. The most important compound in odorant terms was acetoin (3-hydroxy-2-butanone), with OAVs of about 40 in the musts fermented to $4 \%(\mathrm{v} / \mathrm{v})$ ethanol. Like 2,3-butanedione, acetoin is a typical component of musts from Pedro Ximenez cv. grapes dried in the sun or in a chamber, and increases during drying. This compound behaved similarly to 2,3-butanedione, but differed even more markedly between the two types of fermented must. Although acetoin is a typical product of alcoholic fermentation, it can also come from other sources, including yeasts and bacteria, or malolactic bacteria. However, sweet dessert wines fortified halfway through fermentation were found to contain more acetoin than identical wines allowed to ferment completely. This has been ascribed to the high levels of acetoin present in the middle of the process, which subsequently decreases from the effect of its conversion to 2,3-butanediol (Herraiz, 1990).

1-Butanol, ethyl lactate, 3-ethoxypropanol, isobutanoic acid, $\gamma$-butyrolactone and 3-methylbutanoic acid were present at high concentrations as a result of the alcoholic fermentation, but exhibited no odorant activity in most of the wines studied. None of the other compounds studied reached its perception threshold.

As can be seen from Table 3, the compounds exhibiting odorant activity at the end of partial fermentation of the musts remained active during the 30 days of accelerated aging. This was particularly so with 2,3-butanedione and isoamyl acetate, which were the most interesting compounds in terms of OAVs at this stage, irrespective of the wood chip concentration used; both compounds increased in the two types of fermented must. 2,3-Butanedione also increased during the oxidative ageing of Pedro Ximenez sweet musts (Chaves et al., 2007), probably as a result of the oxidation of acetoin or the gradual decrease in the levels of $\mathrm{SO}_{2}$ because of its addition to the carbonyl groups in diacetyl. The reversible and exothermal nature of this reaction could change the "buttery" flavour of wines (Bartowsky \&
Henschke, 2004), an effect that can also be observed in sweet wines. The increase in isoamyl acetate may be related to the high values of acetic acid in the wines in the presence of oak chips, measured as volatile acidity (Table 2).

Among the compounds not present in the fermented musts but extracted from the wood chips, only eugenol and vanillin surpassed their perception threshold, and only in a few samples. In this sense, vanillin was only active in the samples treated with a $2 \mathrm{~g} / \mathrm{L}$ concentration of oak chips, with $\mathrm{OAV} \approx 3$ irrespective of the alcohol content reached by the wines. This compound is one of the most phenolic aldehydes in wine and is responsible for the typical vanilla notes of wines aged in wood casks (Singleton, 1995). Most phenol aldehydes come from the wood and are present at negligible concentrations in the base wine. Therefore, drying and toasting the wood used to age wine influences the extent to which these aldehydes (and, especially, vanillin) are extracted from it. Eugenol was active in the sweet wines treated with a 1 or $2 \mathrm{~g} / \mathrm{L}$ concentration of oak chips, which imparted a typical clove aroma.

Although furfural and 5-methylfurfural form during the grape-drying process (Ruiz et al., 2010), oxidation and the presence of wood chips in the medium increased their contents markedly, albeit below their perception thresholds. However, these compounds might be useful as markers for the ageing process, since their levels are highly correlated with the ageing time (Camara et al., 2006). The (E) and (Z) isomers or oak lactone ( $\beta$-methyl- $\gamma$-octalactone) were only detected in the samples treated with oak chips; however, both exhibited $\mathrm{OAV}<1$. Other volatile phenols, including guaiacol, 4-ethylguaiacol, 4-ethylphenol, syringol and isoeugenol, exhibited increased contents after the accelerated ageing of the wines.

\section{Odorant terms}

To compare the aroma profiles of the wines studied by considering a small number of variables, we used the OAV for the compound grouped into nine odorant terms according to their similar odour descriptors (caramelised, tropical fruit, tree fruit, spicy, pungent floral, chemical, toasted, and lactic). The remaining terms listed in Table 1 are not significant. The addition of the OAVs of the compounds to each term cannot be interpreted as an arithmetical addition of odorant sensations. Several authors have used odorant terms and aromatic series to establish aroma profiles for musts and wines from different winemaking processes (Zea et al., 2007; Ruiz et al., 2010; Gómez García-Carpintero et al., 2012; López de Lerma et al., 2012). In any case, the proposed method is valid for comparing wines of the same type (sweet wines in this work), because the odorant terms always comprise the same compounds. However, this method of studying the aroma profile has the advantage that it strongly reduces the number of variables to be interpreted, preserving their relative importance according to the OAVs of the compounds assembled.

Figure 2 shows the aroma fingerprint of the samples as obtained from the components with $\mathrm{OAV}>1$. As can be seen, the profile was altered considerably by the fermentation process. Overall, the musts fermented to $8 \%(\mathrm{v} / \mathrm{v})$ ethanol exhibited higher OAVs; and the caramelised term had a 
significantly higher OAV in the musts fermented to $4 \%(\mathrm{v} / \mathrm{v})$ ethanol. After the addition of oak chips, the terms caramelised and also, to a lesser extent, spicy, exhibited an increase in the OAVs in both types of wines, as did the tropical fruit term in those wines with the higher alcohol content. Also, ageing introduced the term toasted, which was absent from the samples to which no wood chips had been added.

A principal component analysis (PCA) on the OAVs of the odorant terms considered was conducted in order to identify those with the greatest influence on the aroma profile of sweet wines (Fig. 3). The first two principle components (PCs) jointly accounted for $87 \%$ of the overall variance. PC1 explained $72 \%$ of the variance and encompassed the tropical fruit, tree fruit, pungent and floral terms, which afforded discrimination according to the alcohol content reached by the samples. The musts fermented to $8 \%(\mathrm{v} / \mathrm{v})$ ethanol aged with oak chips were slightly different from those without chips. Since these wines exhibited the highest scores in this

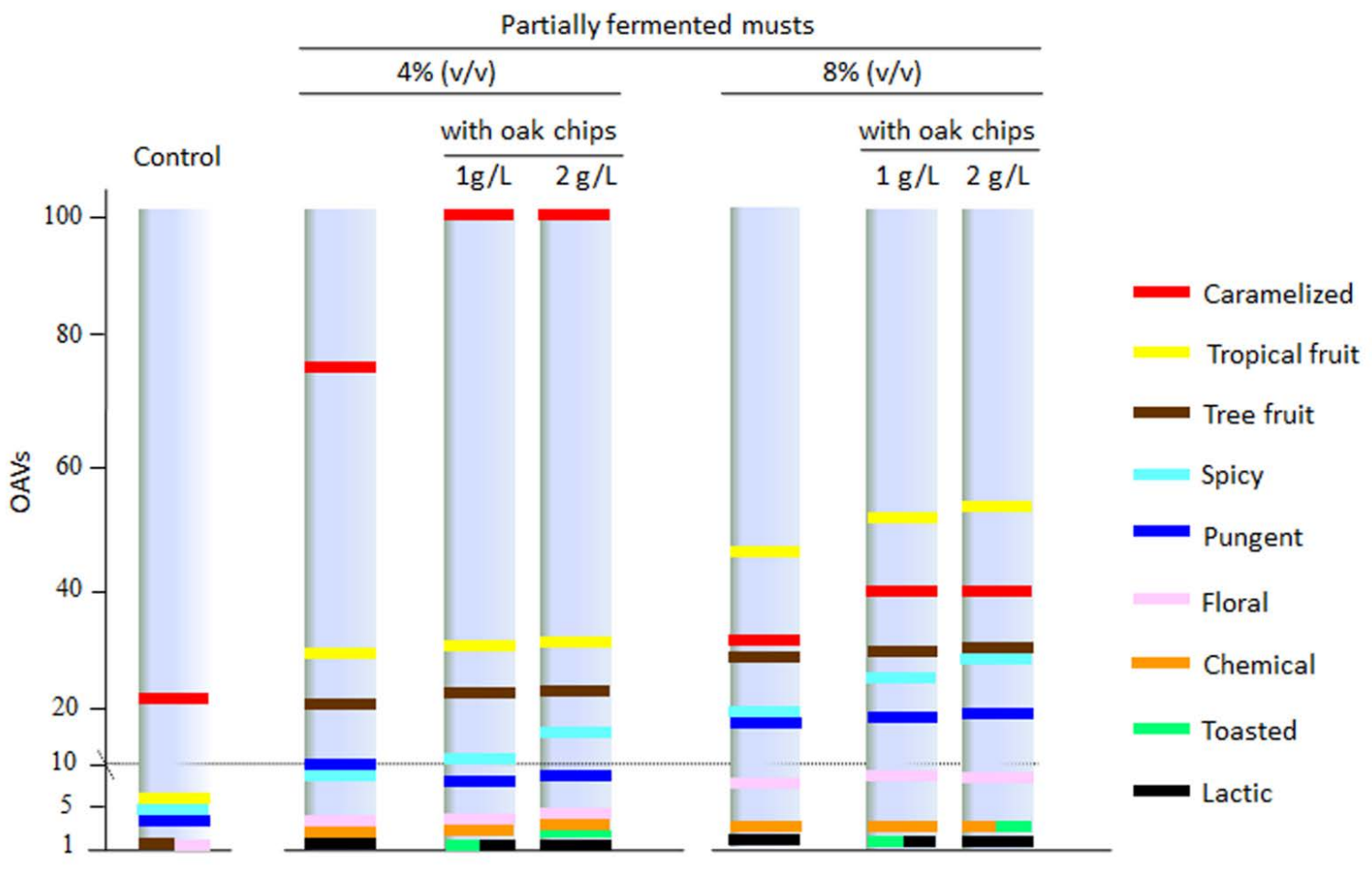

FIGURE 2

Aroma fingerprint of the control must (unfermented), and the musts partially fermented to $4 \%$ (v/v) or $8 \%$ (v/v) of ethanol and to which oak chips subsequently were added $(1 \mathrm{~g} / \mathrm{L}$ or $2 \mathrm{~g} / \mathrm{L})$ for 30 days.

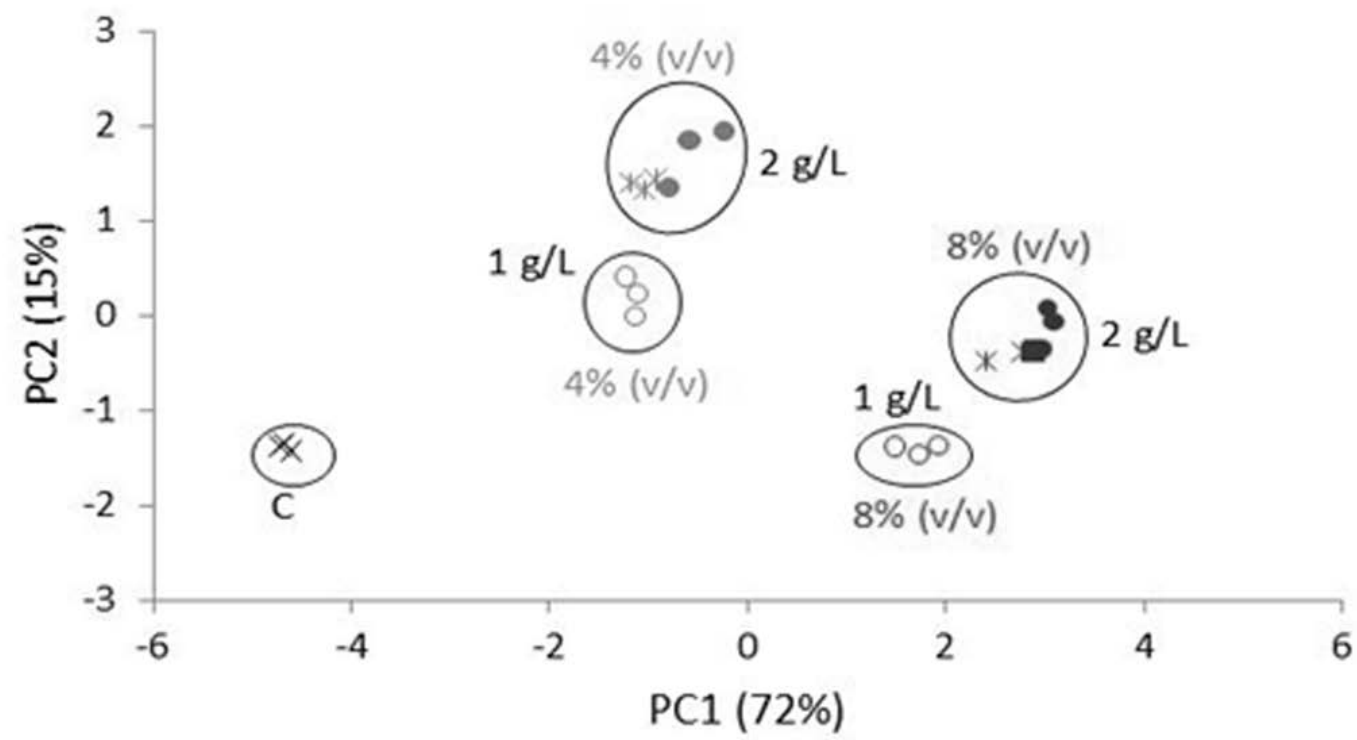

FIGURE 3

Principal component analysis carried out on the OAVs of the odorant terms of the control must (unfermented, C), and the musts partially fermented to $4 \%(\mathrm{v} / \mathrm{v})$ or $8 \%(\mathrm{v} / \mathrm{v})$ of ethanol and to which oak chips subsequently were added ( $1 \mathrm{~g} / \mathrm{L}$ or $2 \mathrm{~g} / \mathrm{L})$ for 30 days. 
component, the tropical fruit, tree fruit, pungent and floral terms showed the highest OAVs, distinguishing them even more clearly from the unfermented musts. Thus, the musts partially fermented to $8 \%(\mathrm{v} / \mathrm{v})$ ethanol displayed a more intense aroma than the unfermented musts, which were reminiscent of the aroma of commercial sweet wines from raisins. PC2 explained $15 \%$ of the variance and encompassed the terms caramelised and toasted. It discriminated between the musts according to whether they were subjected to accelerated ageing, with those fermented to $4 \%(\mathrm{v} / \mathrm{v})$ ethanol exhibiting the highest scores.

\section{Sensory analysis}

To evaluate the different conditions of the winemaking process used in sensorial terms, the sweet wines obtained were subjected to sensory analysis. Using the opinion of the judges it was possible to estimate the acceptability of sweet wines for the consumer and compare the products with other typical wines from the Montilla-Moriles region.

Fig. 4 shows the primary differences established by the sensory analysis of the partially fermented musts, namely differences in acidity, sweetness, balance and global impression. The musts fermented to $4 \%(\mathrm{v} / \mathrm{v})$ ethanol were judged sweeter and less acidic than the others. The tasters distinguished between the musts fermented to identical ethanol content but treated with different concentrations of oak chips; thus, the musts fermented in the presence of a $2 \mathrm{~g} / \mathrm{L}$ concentration were better scored for attributes such as woody and astringent. These results are somehow related to the balance and global impression scores, which were higher for the musts fermented to $8 \%(\mathrm{v} / \mathrm{v})$ ethanol and aged in the presence of a $2 \mathrm{~g} / \mathrm{L}$ concentration of oak chips, probably as a result of their reduced sweetness/acidity ratio. This, in combination with the perception of woody and astringent notes, led to higher global impression scores for these sweet wines.

a)

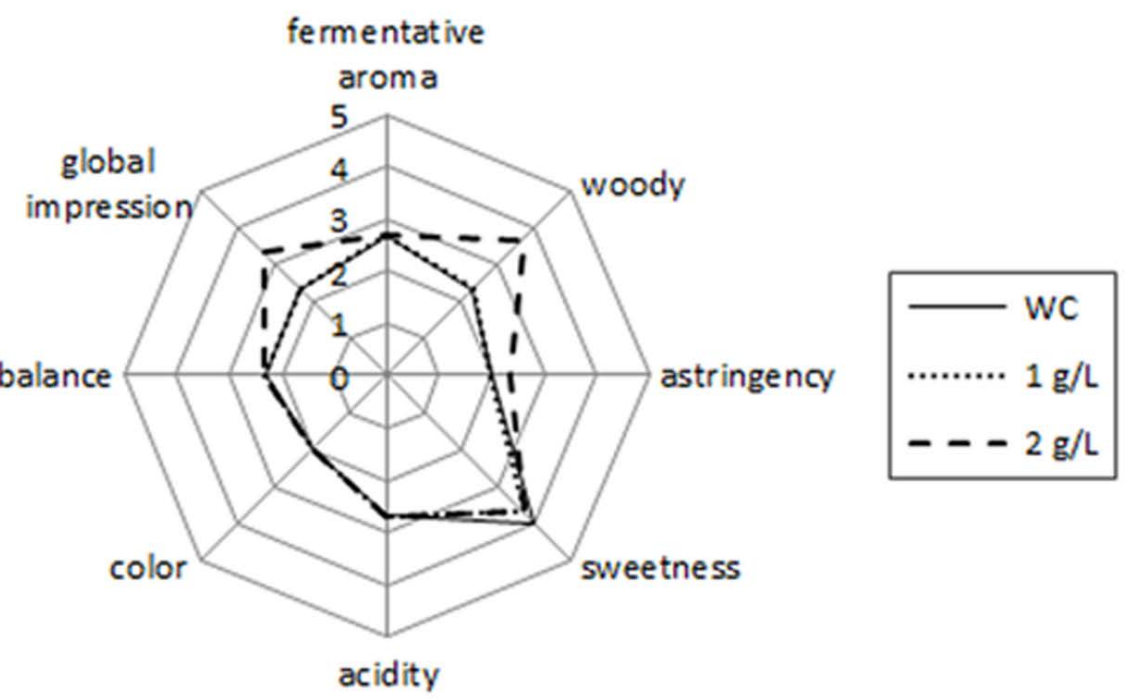

b)

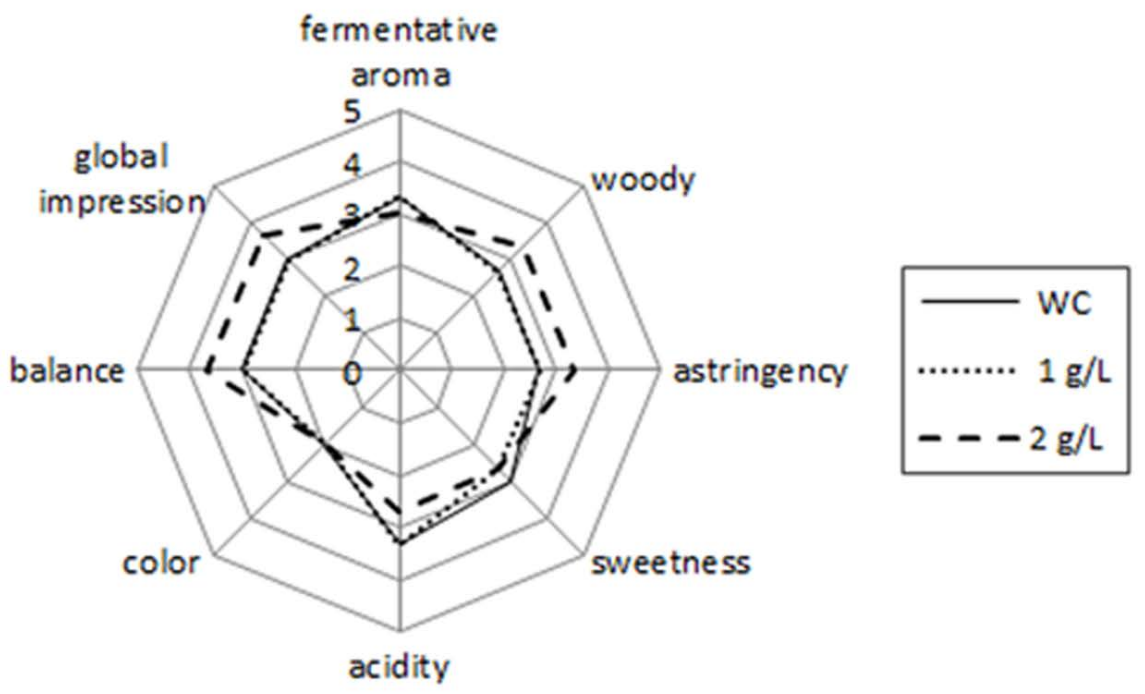

FIGURE 4

Spider web graph for the musts partially fermented to a) $4 \%(\mathrm{v} / \mathrm{v})$ or b) $8 \%(\mathrm{v} / \mathrm{v})$ of ethanol and to which oak chips subsequently were added $(1 \mathrm{~g} / \mathrm{L}$ or $2 \mathrm{~g} / \mathrm{L})$ for 30 days and without chips (WC). 


\section{CONCLUSIONS}

The oenological parameters (Table 2) demonstrate that the partial fermentation of musts has developed normally. Furthermore, these parameters differed markedly between unfermented and partially fermented musts. The results reveal that fermentation reduced brownness, while ageing increased it. In this study, the OAVs of the compounds were grouped into nine odorant terms to compare the aroma profile of wines; this provided a simple and practical method by reducing the number of variables representing the aroma fingerprint of the samples. The tropical fruit term had higher OAVs in the musts fermented to $8 \%(\mathrm{v} / \mathrm{v})$ ethanol; also, the presence of wood chips in the medium introduced the toasted term. The caramelised term showed the highest OAVs in the musts fermented to $4 \%(\mathrm{v} / \mathrm{v})$ ethanol. The opinion of the judges was that the musts fermented to $8 \%(\mathrm{v} / \mathrm{v})$ ethanol and aged in the presence of wood chips at a concentration of 2 $\mathrm{g} / \mathrm{L}$ received the best balance and global impression scores, probably as a result of their low sweetness/acidity ratio, their woody and astringent notes and the increased levels of glycerine. Partial fermentation of the musts from chamberdried grapes and subsequent ageing with oak chips provided a viable procedure to obtain high-quality sweet wines from raisin, and thus to achieve a diversification to meet market demands.

\section{LITERATURE CITED}

Bartowsky, E. \& Henschke, P., 2004. The 'buttery' attribute of winediacetyl-desirability, spoilage and beyond. Int. J. Food Microbiol. 96, 235252.

Camara, J.S., Alves, M.A. \& Marques, J.C., 2006. Changes in volatile composition of Madeira wines during their oxidative ageing. Anal. Chim. Acta 563, 188-197.

Chaves, M., Zea, L., Moyano, L. \& Medina, M., 2007. Changes in colour and odorants compounds during oxidative ageing of Pedro Ximenez sweet wines. J. Agric. Food Chem. 55, 3592-3598

Chkaiban, L., Botondi, R., Bellincontro, A., De Santis, D., Kefalas, P. \& Mencarelli, F., 2007. Influence of postharvest water stress on lipoxygenase and alcohol dehydrogenase activities in the composition of some volatile compounds of Gewürztraminer grapes dehydrated under controlled and uncontrolled thermohygrometric conditions. Aust. J. Grape Wine Res. 13, 142-149.

CIE, 2004 ( $3^{\text {rd }}$ ed). Colourimetry, Commission Internationale de L' Eclairage, Vienna, Austria.

Crowell, E.A. \& Ough, C.S., 1979. A modified procedure for alcohol determination by dichromate oxidation. Am. J. Enol. Vitic. 30, 61-63.

EEC, 1990. Official Report of the European Community, Mundi-Prensa, Madrid, Spain.

Erasmus, D.J., Cliff, M. \& Van Vuuren, H.J., 2004. Impact of yeast strain on the production of acetic acid, glycerol, and the sensory attributes of Icewine. Am. J. Enol. Vitic. 55, 371-378

García-Martínez, T., Bellincontro, A., López de Lerma, M.N., Peinado, R.A., Mauricio, J.C., Mencarelli, F. \& Moreno, J.J., 2011. Discrimination of sweet wines partially fermented by two osmo-ethanol-tolerant yeasts by gas chromatographic analysis and electronic nose. Food Chem. 127, 1391-1396.

Gómez García-Carpintero, E., Gómez Gallego, M.A., Sánchez-Palomo, E. \& González Viñas, M.A., 2012. Impact of alternative technique to ageing using oak chips in alcoholic or in malolactic fermentation on volatile and sensory composition of red wines. Food Chem. 134, 851-863.
Guchu, E., Díaz-Maroto, M.C., Pérez-Coello, M.S., González-Viñas, M.A. \& Cabezudo-Ibáñez, M.D., 2006. Volatile composition and sensory characteristics of Chardonnay wines treated with American and Hungarian oak chips. Food Chem. 99, 350-359.

Herraiz, T., 1990. Production of volatile compounds by Saccharomyces cerevisiae during the alcoholic fermentation of grape must in presence or absence of $\mathrm{SO}_{2}$. Belg. J. Food Chem. Biotechnol. 45, 57-62.

López de Lerma, N., Bellincontro, A., Mencarelli, F., Moreno, J. \& Peinado, R., 2012. Use of electronic nose, validated by GC-MS, to establish the optimum off-vine dehydration time of wine grapes. Food Chem. 130, 447 452.

Malacrino, P., Tosi, E., Caramia, G., Prisco, R. \& Zapparoli, G., 2005. The vinification of partially dried grapes: A comparative fermentation study of Saccharomyces cerevisiae strains under high sugar stress. Lett. Appl. Microbiol. 40, 466-472.

Martineau, B., Acree, T.E. \& Henick-Kling, T., 1995. Effect of wine type on the detection threshold for diacetyl. Food Res. Int. 28, 139-143.

Mérida, J., López-Toledano, A., Márquez, T., Millán, C., Ortega, J.M. \& Medina, M., 2005. Retention of browning compounds by yeasts involved in the winemaking of sherry type wines. Biotechnol. Lett. 27, 1565-1570.

Moreno, J.A., 2005. Influencia del tipo de envejecimiento sobre el perfil aromático de vinos generosos andaluces. Thesis, University of Cordoba, Faculty of Sciences, 14014 Córdoba, Spain.

Moyano, L., Chaves, M. \& Zea, L., 2012. A technical alternative to aging sherry wine. J. Agric. Sci. Appl. 1, 116-121.

Peinado, R., Moreno, J.A., Muñoz, D., Medina, M. \& Moreno, J., 2004. Gas chromatographic quantification of major volatile compounds and polyols in wine by direct injection. J. Agric. Food Chem. 52, 6389-6393.

Pérez-Magariño, S., Ortega-Heras, M. \& Gónzalez-Sanjosé, M.L., 2011 Wine consumption habits and consumer preferences between wines aged in barrels or with chips. J. Sci. Food Agric. 91, 943-949.

Pérez-Serradilla, J.A. \& Luque de Castro, M.D., 2008. Role of lees in wine production: A review. Food Chem. 111, 447-456.

Pigeau, G., Martin, S., Pitkin, C. \& Inglis, D., 2002. The hyperosmotic stress response of wine yeast induced by fermentable sugars during Ice-wine fermentation and its relation to gene expression and metabolites specific to this wine. Brock University Press, Ontario, Canada.

Pigeau, G.M., Bozza, E., Kaiser, K. \& Inglis, D.L., 2007. Concentration effect of Riesling Ice-wine juice on yeast performance and wine acidity. J. Appl. Microbiol. 103, 1691-1698.

Rodríguez-Bencomo, J.J., Ortega-Heras, M., Pérez-Magariño, S., GónzalezHuerta, C. \& Gónzalez-Sanjosé, M.L., 2008. Importance of chip selection and elaboration process on the aromatic composition of finished wines. J. Agric. Food Chem. 56, 5102-5111.

Ruiz, M.J., Zea, L., Moyano, L. \& Medina, M., 2010. Aroma active compounds during the drying of grapes cv. Pedro Ximenez destined to the production of sweet Sherry wine. Eur. Food Res. Technol. 230, 429-435.

Singleton, V.L., 1995. Maturation of wines and spirits: Comparison, facts, and hypotheses. Am. J. Enol. Vitic. 46, 98-115.

Stone, H., Bleibaum, R. \& Thomas, H., 2012 (4th ed.). Sensory evaluation practices. Academic Press, California.

Zea, L., Moyano, L., Moreno, J.A. \& Medina, M., 2007. Aroma series as fingerprints for biological ageing in fino sherry-type wines. J. Sci. Food Agric. 87, 2319-2326. 